\title{
Causes of asymptomatic trocar site hernia: How can it be prevented?
}

\author{
Oguzhan Dincel, ${ }^{1}$ Fatih Basak, ${ }^{2}$ Mustafa Goksu ${ }^{1}$ \\ ${ }^{1}$ Department of General Surgery, Adiyaman University Faculty of Medicine, Adiyaman, Turkey \\ 2Department of General Surgery, Umraniye Training and Research Hospital, Istanbul, Turkey
}

\begin{abstract}
OBJECTIVE: The aim of this study is to evalute risk factors which trigger the development of trocar site hernia after elective laparoscopic cholecystectomy operation and to discuss what needs to be done to prevent it.

METHODS: Patients operated with laparoscopic cholecystectomy between 2011 and 2013 were evaluated. Patients were called back for follow-up visit at 12 month after operation. Physical and ultrasonographic examinations were performed at follow-up. Factors that facilitate development of trocar site hernia were investigated.

RESULTS: One hundred and ninty patients were operated during the study period. One hundred and thirty-two patients who had been examined at follow-up period were included in the study. Mean age of the patients was $50.64 \pm 11.86$ (18-76) years and female /male ratio was five. Trocar site hernia was detected in four patients at umblical trocar site. One of these patients had chronic obstructive lung disease, two of them had diabetes and three of them had obesity. Advanced age and obesity were found to be statistically significant in patients having trocar site hernia ( $p$ value: 0.007 , and 0.008 , respectively).
\end{abstract}

CONCLUSION: Development of trocar site hernia after laparoscopic surgery may be prevented by repair of trocar site in patients taken into consideration risk factors such as advanced age and obesity.

Keywords: Hernia; laparoscopic cholecystectomy; trocar site.

$\mathrm{L}$ aparoscopic cholecystectomy has been firstly done by Mouret in 1987. Use of laparoscopy did not remain limited to gallbladder operations and it has been dramatically increased for the last two decades [1]. Although the frequent use of laparoscopy decreased the risk for the development of large incisional hernia, which is likely to develop after an open surgery, laparoscopic trocar site hernias may be seen, even if rarely. Trocar site hernia
(TSH) is the hernia that develops in the laparoscopic entry site and this complication may result in severe morbidity and mortality in case of intestinal strangulation within hernia [2].

A case of TSH who developed small intestinal obstruction following laparoscopic cholecystectomy was firstly reported by Maio et al. in 1991 [3]. Although this complication potentially results in important problems, it may be missed due to indistinct

Received: July 10, 2015 Accepted: November 11, 2015 Online: December 25, 2015

Correspondence: Dr. Oguzhan DINCEL. Adiyaman Universitesi Tip Fakultesi,

Genel Cerrahi Anabilim Dali, Adiyaman, Turkey.

Tel: +90 416 - 7816131 e-mail: droguzhandincel@yahoo.com

(c) Copyright 2015 by Istanbul Northern Anatolian Association of Public Hospitals - Available online at www.kuzeyklinikleri.com 
clinical signs. The incidence of TSH ranges between $0.18 \%$ and $2.8 \%$ in the studies performed with large series. As a widely accepted condition, many cases cannot be diagnosed due to the lack of long-term follow-ups and thereby, the actual incidence is expected to be higher $[4,5]$.

In this study, we aimed to present our asymptomatic cases of TSH, which developed in the early period after laparoscopic cholecystectomy and to evaluate the relevant risk factors. Furthermore, we targeted to discuss the issue in the light of the existing literature.

\section{MATERIALS AND METHODS}

Written informed consent was obtained from patients who participated in this study. We enrolled the patients who had unergone elective laparoscopic cholecystectomy with the indication of cholecystolithiasis between 2011 and 2013 in the study. Priorly an abdominal transverse incision under the umblicus was made. Then the abdomen was inflated using aVeress needle and $10-\mathrm{mm}$ trocar was introduced into abdomen. Patients who underwent trocar incision using open surgery and those whose incisions were enlarged to extract the gallbladder were excluded from the study. Trocars with a caliber of $10-\mathrm{mm}$ were introduced through the epigastric area and 5-mm trocars were inserted through the right upper and lower quadrants. Gallbladder was removed through epigastric port and trocar sites were not closed with suture.

All patients received prophylactic antibiotic. Skin sutures were removed at day 10 .

Body mass index above $30 \mathrm{~kg} / \mathrm{m}^{2}$ was considered as obesity. Age, gender and comorbidity status of the patients and the presence of obesity were recorded. Patients were called for a control visit at postoperative $12^{\text {th }}$ month. The presence of TSH was evaluated on physical examination. The presence of hernia was confirmed ultrasonographically. The study protocol was approved by the Local Ethics Committee.

\section{Statistical analysis}

For statistical analyses, GraphPad Prism (v6.0, GraphPad Software, Inc., USA) Software was used. Study data were evaluated using descriptive statistics (mean, standard deviation, frequency, rate) whereas intergroup comparisons of the parameters that show normal distribution and the evaluation of the mean values of two groups were performed using Student's t test. Qualitative data were compared using chi-square test and Fisher's Exact Test. Results were evaluated within 95\% confidence interval and $p<0.05$ was considered as the level of significance.

\section{RESULTS}

During the course of the study, 190 patients underwent laparoscopic cholecystectomy. Fifty-eight patients who did not attend to their scheduled followup visits were excluded and 132 patients who were followed-up were enrolled to the study. Of these patients, 110 were female and 22 were male (female/ male $=5$ ). Mean age was $50.64 \pm 11.86$ years (age range $18-76$ years). Fourteen $(10.6 \%)$ patients had also diabetes and eight (6\%) patients had chronic obstructive pulmonary disease (COPD). Eighteen (13.6\%) patients were obese.

In our study, we detected TSH in four patients, all being localized in the umbilical region. During the study and the follow-up periods, none of the patients were re-admitted with TSH symptoms. Patients in whom hernia was detected were diagnosed based on physical examination and ultrasound findings. Patient characteristics are given in Table 1. Gender of the patients was not found to be a significant factor for the development of TSH $(p=1.000)$. It was seen that advanced age was significantly correlated with the development of TSH $(p=0.007)$. Comorbid diseases, diabetes and COPD were evaluated and any effect of these diseases on the development of TSH was not seen $(p=0.055$ and $p=0.223$, respectively). However, presence of obesity had a statistically significant effect on the development of TSH $(p=0.008)$.

\section{DISCUSSION}

Tonouchi classified the types of TSH in three groups in 2004 as follows:. Early-onset type: It results from the rupture of the anterior and posterior 
TABLE 1. Patients' characteristics

\begin{tabular}{|c|c|c|c|c|c|}
\hline \multirow[t]{2}{*}{ Total $(n=132)$} & \multicolumn{2}{|c|}{ TSH negative } & \multicolumn{2}{|c|}{ TSH positive } & \multirow[t]{2}{*}{$p^{*}$} \\
\hline & $\mathrm{n}$ & $\%$ & $\mathrm{n}$ & $\%$ & \\
\hline Number of patients & 128 & 97 & 4 & 3 & \\
\hline Mean age $($ Mean \pm SD) & \multicolumn{2}{|c|}{$50.16 \pm 11.70$} & \multicolumn{2}{|c|}{$66.25 \pm 2.98$} & $0.007 * *$ \\
\hline Female/Male & \multicolumn{2}{|c|}{$106 / 22$} & \multicolumn{2}{|c|}{$4 / 0$} & 1.000 \\
\hline Diabetes Mellitus & 12 & 9.3 & 2 & 50 & 0.055 \\
\hline Chronic obstructive pulmonary disease & 7 & 5.4 & 1 & 25 & 0.223 \\
\hline Obesity & 15 & 11.7 & 3 & 75 & $0.008^{* *}$ \\
\hline
\end{tabular}

TSH: Trocar site hernia; SD: Standard deviation; *t test, Fisher's Exact test; $* * \mathrm{p}<0.05$.

fascial planes in the early post-operative period. Small intestinal obstruction is commonly seen. Late-onset type: It results from the rupture of the anterior and posterior fascial planes several months after the operation. Small intestinal obstruction is not seen and it manifests as an asymptomatic swelling. Special type: It results from the rupture of whole abdominal wall immediately after the operation and there is no hernia sac [6]. All of our cases were asymptomatic and were thought to represent the late-onset type.

Some risk factors that promote the development of TSHs have been demonstrated. These factors include advanced age, diabetes, smoking, increased body mass index, infection at the trocar site, enlargement of the trocar site, trocar diameter and type, the localization area of the trocar and the defects greater than the diameter of the trocar. It was found that especially lower quadrant incisions made for insertion of the trocar which does not contain rectal sheath increase the predisposition to hernia development $[1,5,6,7,8]$.

In many studies, it has been demonstrated that more than $80 \%$ of the TSHs originate from the site resulting from the location $10 \mathrm{~mm}$ above the trocar entry site. However, in a substantial number of studies, the investigators also detected hernias resulting from the defects of the trocars with calibers smaller than $5 \mathrm{~mm}$ in the presence of risk factors. Therefore, many authors recommend that entry sites resulting from the trocars sized $10 \mathrm{~mm}$ or above should be closed $[5,7,8]$. In some studies, it was recommended that the trocar defects with a size of $10 \mathrm{~mm}$ or below should be repaired in the presence of some risk factors such as advanced age, obesity, diabetes and long lasting interventions [9, 10]. All hernias observed in our study originated from the $10 \mathrm{~mm}$-long trocar sites in the umbilical region, while no hernia was observed in 5- $\mathrm{mm}$ trocar entry sites.

Literature reviews demonstrated that the obesity is a predisposing factor for TSH but no evidence exists to prove the effect of the body mass index on the incidence of hernia $[5,6,11]$. In a previous study, $50 \%$ of the patients who developed TSH had morbid obesity (body mass index $>40 \mathrm{~kg} / \mathrm{m}^{2}$ ) and $83 \%$ had obesity (body mass index $>30 \mathrm{~kg} / \mathrm{m}^{2}$ ) [12]. Obesity was an important risk factor in some uni- and multivariate studies and, as suggested as a hypothesis in the publications supported by some studies, increased intra-abdominal pressure which creates difficulties for complete closure of the defect play an important role in the development of TSH [11]. Among four TSH cases presented in the present study, three were obese and the presence of obesity was statistically significant in the subjects who developed TSH $(\mathrm{p}=0.008)$.

In some previously published multivariate analyses, the correlation between TSH and the age, which is among the risk factors, was not found to 
be significant. Although age of 70 years or more was not significantly relevant, as a hypothesis, weak fascia and decreased volume of abdominal muscles were reported to be potential risk factors in the elderly [13]. In the study presented herein, evaluation of the age of the patients with TSH yielded significant results and the incidence of TSH was more commonly seen in the advanced age group $(p=0.007)$.

There are some conflicting insights about the potential role of the gender of the patients in the development of TSH. While some reports suggested that the incidence was higher in male patients, another study demonstrated a higher incidence rate in female patients. Although the role of the gender in TSH is conflicting in the literature, the factors that account for TSH appear to be multifactorial rather than being limited to the gender. The fact that the majority of the cases are female may explain the prejudice about the female gender [14]. In our study, the patients with TSH were all female but any statistically significant difference was not detected between genders $(p=1.000)$.

Although the effect of pre-existing diabetes on wound healing is well known, it is difficult to explain this correlation. A similar correlation was detected between incisional hernia and diabetes. In this study, two of four patients with TSH had diabetes but this did not reach statistical significance $(p=0.055)$. It was demonstrated that COPD and abdominal wall infections increased the predisposition to the development of incisional hernia [15]. We think that COPD leads to the development of hernia by delaying the wound healing and by causing cough episodes that increase the intra-abdominal pressure. In one of the TSH cases presented in the study, COPD was present but the effect of COPD on TSH development was not statistically significant $(p=0.223)$.

In the literature, some studies reported pre-existing umbilical hernia as a risk factor. Nassar et al. reported the pre-operative presence of umbilical or paraumbilical hernia in $12 \%$ of the patients $(84 \%$ of them were asymptomatic) who had undergone laparoscopic cholecystectomy. It was reported that, despite primary closure of these defects, $1.8 \%$ of them had developed TSH [14]. Again, Azurin et al. reported similar results in their study. In nine of their ten patients with TSH, umbilical hernia had been detected and repaired during the operation [5]. Our cases did not show any symptoms suggestive of preoperative hernia.

\section{Conclusion}

Trocar site hernia may emerge as an important problem following laparoscopic surgery. Therefore, the trocar entry site defects greater than $10 \mathrm{~mm}$ should be routinely closed and the defects with a size of $10 \mathrm{~mm}$ that cannot be enlarged should be absolutely closed in the presence of any risk factor, such as age and obesity.

The present study does not allow for any comment on the closure of the trocar defects with a size of $5 \mathrm{~mm}$, but some studies recommend their closures. Especially the people with risk factors should be informed about the likelihood of hernia development and an earlier diagnosis should be ensured.

Development of trocar site hernia after laparoscopic surgery may be prevented by repair of the trocar site in patients who have risk factors such as advanced age and obesity.

Informed Consent: Written informed consent was obtained from the patients who participated in this study.

Conflict of Interest: No conflict of interest was declared by the authors.

Financial Disclosure: The authors declared that this study has received no financial support.

\section{REFERENCES}

1. Coda A, Bossotti M, Ferri F, Mattio R, Ramellini G, Poma A, et al. Incisional hernia and fascial defect following laparoscopic surgery. Surg Laparosc Endosc Percutan Tech 2000;10:34-8.

2. Lee JH, Kim W. Strangulated small bowel hernia through the port site: a case report. World J Gastroenterol 2008;14:6881-3.

3. Maio A, Ruchman RB. CT diagnosis of postlaparoscopic hernia. J Comput Assist Tomogr 1991;15:1054-5.

4. Swank HA, Mulder IM, la Chapelle CF, Reitsma JB, Lange JF, Bemelman WA. Systematic review of trocar-site hernia. Br J Surg 2012;99:315-23.

5. Azurin DJ, Go LS, Arroyo LR, Kirkland ML. Trocar site herniation following laparoscopic cholecystectomy and the sig- 
nificance of an incidental preexisting umbilical hernia. Am Surg 1995;61:718-20.

6. Tonouchi H, Ohmori Y, Kobayashi M, Kusunoki M. Trocar site hernia. Arch Surg 2004;139:1248-56.

7. Ahmad SA, Schuricht AL, Azurin DJ, Arroyo LR, Paskin DL, Bar AH, et al. Complications of laparoscopic cholecystectomy: the experience of a university-affiliated teaching hospital. J Laparoendosc Adv Surg Tech A 1997;7:29-35.

8. Freedman AN, Sigman HH. Incarcerated paraumbilical incisional hernia and abscess--complications of a spilled gallstone. J Laparoendosc Surg 1995;5:189-91.

9. Reardon PR, Preciado A, Scarborough T, Matthews B, Marti JL. Hernia at 5-mm laparoscopic port site presenting as early postoperative small bowel obstruction. J Laparoendosc Adv Surg Tech A 1999;9:523-5.

10. Paya K, Wurm J, Fakhari M, Felder-Puig R, Puig S. Trocarsite hernia as a typical postoperative complication of minimally invasive surgery among preschool children. Surg Endosc 2008;22:2724-7.
11. Hussain A, Mahmood H, Singhal T, Balakrishnan S, Nicholls J, El-Hasani S. Long-term study of port-site incisional hernia after laparoscopic procedures. JSLS 2009;13:346-9.

12. Agaba EA, Rainville H, Ikedilo O, Vemulapali P. Incidence of port-site incisional hernia after single-incision laparoscopic surgery. JSLS 2014;18:204-10.

13. Mayol J, Garcia-Aguilar J, Ortiz-Oshiro E, De-Diego Carmona JA, Fernandez-Represa JA. Risks of the minimal access approach for laparoscopic surgery: multivariate analysis of morbidity related to umbilical trocar insertion. World J Surg 1997;21:529-33.

14. Nassar AH, Ashkar KA, Rashed AA, Abdulmoneum MG. Laparoscopic cholecystectomy and the umbilicus. Br J Surg 1997;84:630-3.

15. Beltrán MA, Cruces KS. Incisional hernia after McBurney incision: retrospective case-control study of risk factors and surgical treatment. World J Surg 2008;32:596-603. 